\title{
The role of the caudate in nonmotor behaviors in Huntington's disease
}

\author{
D.H. Jacobs and S.J. Huber* \\ Department of Neurology, University of Kansas School of Medicine, Kansas City, \\ Kansas, USA \\ Correspondence to: D.H. Jacobs, Department of Neurology, Box J-236, Shands Hospital, \\ Gainesville, FL 32610, USA
}

\begin{abstract}
Neuropsychologic data suggest an important role for the caudate nucleus $(\mathrm{CN})$ in behavioral impairments in Huntington's disease (HD). These include abnormalities in executive function, egocentric visuospatial representations, communication, and retrieval of declarative memories, changes in personality, and psychiatric disturbances. Animal paradigms of CN lesions support a role for the $\mathrm{CN}$ in some of these behaviors. Current theories of basal ganglia function add explanatory value to the role of the $\mathrm{CN}$ in these behaviors. A disconnection of the caudate from limbic structures, including the amygdala may account for many nonmotor behaviors observed in HD.
\end{abstract}

Keywords: Basal ganglia - Caudate - Chorea - Dementia - Depression - Huntington's disease - Neostriatum - Putamen

\section{INTRODUCTION}

Huntington's disease (HD) is an inherited neurodegenerative disorder characterized by abnormal movements, dementia, and psychiatric and personality abnormalities. The genetic defect in HD is localized to the short arm of chromosome 4. The disease is autosomal dominant and fully penetrant. Characteristically, the onset of HD occurs in adulthood and the course progesses relentlessly, leading to death within two decades. However, clinical variants with earlier and later onsets have been described (Harper, 1991).

Jelgersma (1908) and Alzheimer (1911) were the first to identify degeneration of the caudate nucleus $(\mathrm{CN})$ in HD patients. The dorsomedial aspect of the head and tail of the $\mathrm{CN}$ are affected first; subsequently, neuronal loss sweeps ventrally and laterally. Involvement of the putamen (PUT) and globus pallidus (GP) occurs after $\mathrm{CN}$ involvement. The neuropathologic changes of HD eventually involve many other structures, including the cortex, the subcortical gray and white matter, and the cerebellar and brainstem nuclei. Many of these structures send or receive fibers that synapse in the neostriatum (CN and PUT) (Bruyn et al., 1979; Vonsattel et al., 1985; Roos, 1986; De La Monte et al., 1988). Physiologic imaging studies such as positron emission tomography (PET) also show that the earliest changes in glucose utilization in the brains of HD patients occur in the CN (Mazziotta et al., 1987).

Historically, most physiologists have emphasized the

\footnotetext{
* The contribution of S.J. Huber is posthumous.
}

"extrapyramidal" motor function of the neostriatum at the expense of its nonmotor behavioral functions (KinnierWilson, 1914). The initial studies that extend the role of the $\mathrm{CN}$ in behavior were conducted by Divac. Divac et al. (1967) used models of cortical and CN ablations and electrical stimulations to demonstrate similar independent behavioral functions in parts of the $\mathrm{CN}$ and their cortical projection areas.

The role of the $\mathrm{CN}$ in nonmotor behavior was further refined by descriptions of at least five parallel, anatomically segregated multisynaptic loops which pass from the cortex, through the basal ganglia to the thalamus and return to the frontal lobes (Alexander et al. 1986). These tracts are defined by their cortical representations and within the basal ganglia, by target region and neuropeptide. The classic "motor" loop synapses in the PUT, whereas nonmotor loops, including the lateral orbitofrontal (OF), dorsolateral frontal (DLF), and oculomotor loops synapse within the CN. Subpopulations of projecting neurons have been defined by their target region and neuropeptide that are selectively involved in HD patients (Ferrante et al., 1985; Reiner et al., 1988).

Several lines of evidence support the contention that the $\mathrm{CN}$-synapsing loops may be important for cognitive and emotional functioning, whereas the PUT is more important for motor function. Sensorimotor cortex projects mainly to PUT, whereas higher order association cortices (parietal, temporal, and cingulate) as well as limbic and paralimbic structures (amygdala and hippocampus) pro-

Behavioural Neurology . Vol 5 . 1992

205 
ject topographically to the CN (Selemon and GoldmanRakic, 1985; Parent, 1990, review). Cognitive and emotional changes in HD correlate most closely with abnormalities in the $\mathrm{CN}$ on computed tomography (CT) and PET, whereas chorea correlates with atrophy or dysfunction of the PUT. Neuroimaging abnormalities in other brain areas have been demonstrated but have not been consistently correlated with behavioral deficits (Young et al., 1986; Bamford, 1988; Berent et al., 1988; Starkstein et al., 1988; Starkstein et al., 1989; Kuwert et al., 1990; Jernigan et al., 1991). Thus the CN would appear to play a major role in the cognitive and emotional behavioral abnormalities associated with HD.

Recently, there has been a resurgence of interest in the role of cortical and subcortical structures and neurotransmitter systems in human cognitive and emotional function (Cummings, 1990). In part, that interest has been based on the supposition that "subcortical" dementias such as HD or Parkinson's disease (PD) affect neural systems which involve the neostriatum or other subcortical structures, whereas "cortical" dementias such as Alzheimer's disease (AD) affect different neural systems that mostly spare the neostriatum. HD has highly characteristic behavioral, neuropsychologic and neuropsychiatric changes and represents an ideal pathophysiologic model from which to examine the role of the $\mathrm{CN}$ in human behavior. The primary purpose of this paper is to describe current neuropsychologic studies in HD and to integrate these findings with basic science studies of the $\mathrm{CN}$ to help elucidate the function of the $\mathrm{CN}$.

\section{EXECUTIVE FUNCTION}

Patients with HD with normal verbal and performance IQs may show impairment on neuropsychological tests which measure "elaborative", "executive", or "complex psychomotor" functions including the capacity to plan, organize, sequence, and shift cognitive sets. These deficits include high level cognitive programs that permit creativity and abstract thought, and most commonly occur with dorsolateral frontal lesions. Nondemented HD patients are unable to follow a ten step recipe (Caine et al., 1978) and perform poorly on the Trailmaking Tests, the Wisconsin Card Sorting test, the Stroop Color Card and Stroop Interference Card tests (Josiassen, 1983; Starkstein et al., 1988; Bamford et al., 1989). Performance declines further with progression of disease (Caine et al., 1978; Josiassen et al., 1983; Bamford et al., 1989). Performance on these tests is impaired even in asymptomatic patients who are seropositive for genetic markers of HD and who later develop HD (Jason et al., 1988).

While frontal lobe pathology is described in HD and is often responsible for the abnormal neuropsychological tests described above, $\mathrm{CN}$ lesions alone were, in the case of Divac's animal experiments, capable of producing deficits similar to the ones produced by dorsolateral frontal lesions in experimental paradigms (Divac et al., 1967). The paradigms used by Divac et al. did not test executive function, which is considered a human trait (Fuster, 1989), but did use delayed alternation paradigms requiring planning and spatial choices. Moreover, performance on tests of "executive function" have been correlated with $\mathrm{CN}$ atrophy on CT (Starkstein et al., 1988; Bamford et al., 1989). Consequently, the $\mathrm{CN}$ lesions independently may be considered a possible culprit for these neuropsychological deficits in HD patients.

\section{VISUOSPATIAL FUNCTION}

Visuospatial abnormalities are common in patients with HD. Visuospatial problems in HD include altered perceptions of egocentric space, in which position or movement is defined in relation to the observer. Potegal (1971) found that patients with HD and PD could remember and mark the position of a dot on a piece of paper after they were blindfolded, but that HD patients could no longer perform the task if they moved sideways. Brouwers et al. (1984) found a double dissociation between HD and AD with respect to visuospatial function: HD patients were impaired on tasks of egocentric space (the Street-Map test), but not on tasks involving extrapersonal perception and construction (copying Rey-Osterrieth Complex Figure). AD patients had the opposite profile. Mohr et al. (1991) found that the specific visuospatial dysfunction in HD included items of spatial manipulation. These included matching a rotated three dimensional object to an unrotated original, consistency of judgment of orientation on the In-Front-Of-Test, and right-left judgments on the Street Map Test. These tests negatively correlated with disease duration.

Several reports suggest that HD patients are impaired on performance on subtests of the WAIS including block design and object assembly, but these studies have been criticized methodologically (Norton, 1975; Caine et al., 1978; Fedio et al., 1979; Josiassen, 1983). Butters et al. (1978) found normal WAIS block design subtest in patients with early HD. Since patients with widespread cortical dysfunction may have abnormalities on visuospatial subtests of WAIS (Benton, 1985), investigators proposed discriminating early and late HD patients and testing only the former (Mohr et al., 1991).

In primates, spatial representational tasks involving spatial choices are localized around the principal sulcus, a region homologous to part of the dorsolateral frontal cortex in humans (Goldman-Rakic, 1987). Divac et al. (1967) demonstrated that animal lesions of the anterodorsal part of the head of the $\mathrm{CN}$ or dorsolateral frontal cortex produce deficits in delayed alternation paradigms which 
require spatial choices (left or right). Deficits on delayed alternation may also be produced by injection of kainic acid into the anterior medial CN (Divac et al., 1978) or by bilateral ablations of the prefrontal cortex (Divac, 1972). These findings suggest that the anterodorsal $\mathrm{CN}$ and dorsolateral frontal areas are concerned with spatial problems (Johnson and Rosvold, 1971).

\section{DIGIT SPAN}

On the serial sevens test of the Mini Mental State Exam (MMSE), when subjects are matched for total score, performance of HD patients is lower than AD patients (Folstein et al., 1990). The WAIS subtests differentially decline in early $\mathrm{HD}$, with the most abnormal subtests including Arithmetic, Digit Symbol, Picture Arrangement, and Digit Span (Norton, 1975; Butters et al., 1978; Josiassen, 1983; Pillon et al., 1991). Moreover, HD patients score below expected values on these tests when adjusted for their overall cognitive ability (Fedio et al., 1979). These tests collectively measure concentration, and differentiate HD from AD.

\section{LANGUAGE AND COMMUNICATION DISORDERS}

Language is assumed to be normal in HD until late in the course of the disease. The lack of language deficits may falsely give the impression that these patients are nondemented (Shoulson, 1990). However, language problems must be separated from communication disorders which are not strictly linguistic.

Problems of motoric output which commonly affect prosody in HD patients include dysarthria and respiratory problems (Gordon and Illes, 1987; Podoll et al., 1988). Patients with early HD have hesitations and press of speech. Later in the course, HD patients lose the press of speech while continuing to have reductions in melodic line and articulatory agility. In addition, patients with early HD are impaired on discrimination and comprehension of affective and propositional prosody, a deficit which may contribute to the early social isolation of HD patients (Speedie et al., 1990).

Patients with advanced HD may produce short, syntactically simple but correct sentences and may ultimately become mute (Folstein and McHugh, 1983; Podoll et al., 1988). This problem cannot be considered strictly a motoric speech output problem because agraphia also occurs and may involve inexplicable halts in the act of writing and omission of letters (Gordon and Illes, 1987; Podoll et al., 1988).

Several studies of language in HD have shown that semantics, like syntax are relatively preserved compared with AD. Repetition, writing, word-finding and paraphasic errors in naming have been described in HD (Caine et al.,
1986; Gordon and Illes, 1987); however these findings have been disputed. Moss et al. (1986) found that recognition of verbal stimuli was selectively preserved in HD but not in AD or Korsakoff's syndrome. Others have confirmed relative sparing of semantic content in HD by demonstrating that even late in the disease, only a minority of patients had language problems, most notably with confrontation naming (Bayles and Tomoeda, 1983; Smith et al., 1988; Podoll et al., 1988; Hodges et al., 1991). Analysis of naming error type shows a greater proportion than normal of errors misnaming objects with names of visually similar objects and fewer errors with semantically associated objects (Bayles and Tomoeda, 1983; Podoll et al., 1988; Hodges et al., 1991). The error type analysis implies that defective visual processing (visual naming) rather than flawed semantic associative processing is the primary process. Error-type analysis thus differentiates $\mathrm{HD}$ and $\mathrm{AD}$ patients, as the latter have more semantically related naming errors.

Animal studies support a role for the $\mathrm{CN}$ in some of the disorders of communication described above. Production and comprehension of prosody, gestural language and social pragmatics are considered to comprise paralinguistic aspects of communication which are localized outside the language centers (Heilman et al., 1975; Ross and Mesulam, 1979). Stimulations of monkey CN and PUT cause inhibition of socially important vocalizations, causing the "boss monkey" to temporarily lose his primary status (Delgado, 1963).

Although diminished fluency may represent, in part, a physical adaptation to problems which impair speaking and writing (dysarthria and chorea), electrical stimulations and animal studies suggest an additional neurologic mechanism. CN stimulations in human patients produce hesitations and arrests in speech (Van Buren, 1963). In animals, stimulation of the CN, PUT, globus pallidus, cingulum, orbitofrontal cortex and other structures causes a "behavioral arrest" phenomenon in which animals abruptly cease activity even in midstep (Delgado, 1979, p. 247; Phillips, 1979). The data suggest that lesions of the neostriatum or cortex to which it synaptically connects may affect verbal fluency.

The disorder of visual naming implies a lesion of unimodal visual association cortex or its unimodal connections, supporting Mohr's contention (Mohr et al., 1991) that $\mathrm{HD}$ patients are impaired at recognition of rotated objects. The tail of the CN connects to visual areas in the temporal lobe (Alexander et al., 1986). Jernigan et al. (1991), in an MRI study, found striking volume loss in the inferior temporal-occipital cortex, an area important for visual perceptual processing, as well as in the CN. Divac et al. (1967) found similar deficits in pattern discrimination ability in animals with lesions of the temporal lobe or tail of the $\mathrm{CN}$. 


\section{MEMORY}

Impairment of memory is the most prominent of the cognitive problems in HD. It is present early in the disease course (within twelve months of onset of chorea) and shows only mild progression thereafter (Butters et al., 1976, 1978; Albert et al., 1981; Josiassen et al., 1983). The memory defect spares insight and orientation until late in the disease course.

Distinctions among various types of memory function are commonly confused by multiple nomenclatures. Episodic or declarative memory refers to memory for specific events or facts. Semantic memory refers to memory for words and their meanings, rules of grammar, syntax, arithmetic and general information of the world around us (Bayles and Kaszniak, 1987). Deficits in tests of declarative memory are potentially attributable to problems encoding memories, storing memories, or retrieving them. In $\mathrm{HD}$, several lines of evidence support impaired retrieval as the principal memory problem.

HD patients are impaired on declarative memory tests using free recall (Butters et al., 1978; Caine et al., 1978; Hodges et al., 1990). Unlike patients with Korsakoff's amnesia, patients with HD improve on recognition memory paradigms (Martone, 1984; Massman, 1990). Moreover, HD patients can make "feeling of knowing" judgments on items that cannot be recalled (Brandt, 1985). HD patients fail to remember previously recalled events (Caine et al., 1977). These data suggest that HD patients know more than they are able to recall.

Recognition strategies that are particularly effective are those that involve semantic strategies. Jason et al. (1988) and Lyle and Quast (1976) found low scores on tests of visuospatial memory in at-risk individuals who eventually developed the disease. HD patients are able to recognize pictorial information using verbal mediators (Butters et al., 1983), and perform better than AD patients and Korsakoff's amnestics on recognition for visually presented verbal stimuli (Moss et al., 1986). These data suggest that HD patients have difficulty retrieving memories they have successfully encoded, unless they use semantic strategies to do so.

Further evidence that HD patients suffer primarily retrieval deficits comes from studies which use cues or priming to facilitate recall. Priming elicits unconscious memory stores which cannot be accessed by other cognitive memory systems (Tulving and Schacter, 1990). Investigators have consistently found that HD (but not AD) patients utilize strong and weak lexical and semantic cues to retrieve words with priming nearly to the same extent as normal controls (Shinamura et al., 1987; Granholm and Butters, 1988; Salmon et al., 1988; Smith et al., 1988). HD patients with impaired visuospatial memory can benefit from pictorial priming, again differentiating $\mathrm{HD}$ and $\mathrm{AD}$
(Heindel et al., 1990). Priming studies thus support the idea that lexical, semantic and pictorial priming mechanisms bypass the $\mathrm{CN}$.

Albert et al. (1981) analysed HD patients' abilities to recall remote memories in a comparison with patients with Korsakoff's syndrome. They found the group with Korsakoff's syndrome, but not the HD group, demonstrated a temporal gradient of forgetting with a greater rate of forgetting of more recent events. The data suggest that Korsakoff's patients suffer impairments of their ability to encode new memories, and loss of traces of some old ones, whereas HD patients continue to encode memories but cannot retrieve them.

HD patients demonstrate reduced verbal fluency. HD patients score poorly on a letter fluency task, in which they are asked to generate as many words as possible beginning with F, A, and S (Butters et al., 1978). Additional studies distinguished patients with AD from amnesics and those with HD. AD patients were better able to generate categories (e.g. fruits) than to name exemplars (e.g. apples) in each category. HD patients had difficulty generating either categories or exemplars. Whereas the loss of exemplars in AD has been postulated to be a "bottom-up" breakdown of semantic knowledge, the pattern of equivalent category and exemplar loss in HD may be due to faulty search and retrieval (Butters et al., 1986, 1987; Troster et al., 1989; Hodges et al., 1990). However, Troster and associates also found that more severely demented HD patients had decreased item per category ratios which suggested semantic memory impairment, albeit less than that seen in AD.

Another procedure used to examine the issue is the release from proactive interference (PI) paradigm. When repeated trials of free recall are tested with items from the same semantic class (fruits), performance decreases over trials. When the semantic class of materials to be recalled is changed (animals), performance is better and roughly equals that of the first trial using the initial category of items (fruits). This release from PI is thought to measure semantic encoding. Beatty and Butters (1986) found that $\mathrm{HD}$ patients have a normal release from PI, differentiating $\mathrm{HD}$ from $\mathrm{AD}$, and suggesting that a failure of semantic encoding does not contribute to the episodic memory impairment in HD.

These findings suggest that semantic memory is relatively intact in HD compared with AD. However, "implicit" memory for skill learning may be defective. Martone et al. (1984) demonstrated a double dissociation between HD and Korsakoff's patients on skill learning and recognition tasks. Korsakoff patients performed better at learning the skill, reading mirror reflected word triads, but HD patients were superior at delayed recognition of the words used in the task. Although this study fails to take into account ocular motility and visuospatial problems in $\mathrm{HD}, \mathrm{HD}$ patients also do poorly on a paradigm in which 
they are required to keep their hand on a stylus in contact with a rotating turntable, a task that does not have those methodological problems. In contrast, HD patients perform well on a lexical priming task. AD and Korsakoff's patients have the opposite pattern of results on these two types of implicit tasks (Eslinger and Damasio, 1986; Heindel et al., 1988, 1989; Knopman and Nissen, 1991).

These findings suggested the existence of two independent implicit memory systems, one serving implicit semantic memory, the other serving procedural or skilllearning function. The findings also suggested an anatomic hypothesis, namely that skill learning could be attributable to the neostriatum; that would explain both its impairment in $\mathrm{HD}$ and sparing of its function in $\mathrm{AD}$ and Korsakoff's syndrome. Support for this view comes from studies of neostriatal stimulations in monkeys which suppress previously learned conditioned bar pressing (Kitsikis and Rougeful, 1968). These deficits involving motoric skills could well involve putamen rather than $\mathrm{CN}$ synapsing loops. Other structures potentially important to motoric learning include the cortex and dentate nucleus of the cerebellum (Schmahmann, 1991), which are affected in HD.

The anatomy of the memory problem differs in $\mathrm{AD}$ and HD. Aylward et al. (1991) studied measurements of the suprasellar cisterns in the two groups as an indirect assessment of the hippocampus and enterorhinal cortex. They found that atrophy occurred in both groups, but correlated with dementia only in the AD group.

In summary, the bulk of the evidence suggests that impaired retrieval is the most important mechanism of the anterograde memory defect in HD. Retrieval presumably involves disruption of $\mathrm{CN}$-limbic pathways. Semantic memory is mostly spared in HD, and semantic strategies improve performance on memory tasks. Motor skill-learning impairment in HD hypothetically involves components of the motor "loop".

\section{PERSONALITY AND PSYCHIATRIC FINDINGS}

Personality and psychiatric abnormalities may antedate the movement disorder and cognitive changes by a decade or more in $\mathrm{HD}$, causing considerable disability (Martin and Gusella, 1985).

Personality changes that sometimes occur early in the disease include irritability, impulsivity, and rapidly changing affect. More extensive changes commonly occur after 7-10 years of illness including decreased initiative. Patients may appear to be apathetic and to withdraw from activities and to deny functional disability (Caine et al., 1978; Caine and Shoulson, 1983; Folstein and McHugh, 1983).

Others have noted that despite the seeming apathy, HD patients' motivational systems may be more responsive to external than to internal stimuli. One patient who was chronically dishevelled dramatically improved her appearance before participating in a social occasion that had strong personal meaning (Caine et al., 1978).

Evidence of clustering of psychiatric disorders in certain families suggests a biologic basis (Caine et al., 1978; Mindham et al., 1985; Folstein, 1991). Unipolar depression occurs approximately four times more commonly than bipolar depression. Schizophrenia occurs about $4 \%$ of the time, higher than in the general population but less than reported in earlier literature. Anxiety disorders, panic attacks, obsessive-compulsive disorders and altered sexual behavior are reported. Suicide has been noted to be increased since the original reports of HD (Huntington, 1872) and may occur in early disease or suspected but undiagnosed cases (Schoenfeld et al., 1984). However, not all psychiatric problems in Huntington disease kindreds can be considered biologic. Alcoholism, drug abuse and reactive depression may occur in nonaffected at-risk family members and in spouses (Wexler, 1979; Folstein and McHugh, 1983). Conduct disorders in at-risk children are not predictive of HD (Folstein, 1991).

One poorly understood aspect of personality and psychiatric abnormalities in HD is the anatomic basis. In part this can be attributed to the difficulty of establishing animal models for psychiatric disease. Additionally, these problems can occur prior to other clinical signs or symptoms and in the absence of definite neuropathology. Hypotheses are presented but should be considered in light of the known neuropathology of HD.

One such conjecture is based on the putative presence of $\mathrm{CN}$ neuropathology long before clinical signs appear. Myers et al. (1991) examined Grade O HD brains (those without demonstrable neuropathology in the $\mathrm{CN}$ ) and found $40 \%$ depletion of neuronal counts in the $\mathrm{CN}$ without astrocytosis. They concluded that neuronal loss in the $\mathrm{CN}$ was longstanding. Their view is supported by clinical studies which demonstrate a "zone of onset" in which atrisk patients who later develop HD have minor abnormalities in the neurologic examinations (Penney et al., 1990). PET studies have also shown decreased glucose metabolism in some at-risk patients (Mazziotta et al., 1987; Young et al., 1987; Grafton et al., 1990). Thus, affective disorders can precede the clinical diagnosis by several years yet still conceivably result from the known neuropathology of HD.

Assuming that emotional and psychiatric changes are biological manifestations of $\mathrm{HD}$, several studies suggest the importance of the orbitofrontal loop. Emotional lability or impaired response inhibition, which is seen early in HD, classically occurs in patients with orbitofrontal lesions. However, it also might reflect disruption of the orbitofrontal loop at the level of the $\mathrm{CN}$. Lesions in the ventrolateral head of the $\mathrm{CN}$ or orbitofrontal cortex prod- 
uce identical deficits on object reversal tasks and go, no go paradigms requiring suppression of competing response tendencies (Divac et al., 1967). Lesions in the head of the $\mathrm{CN}$ or electrical stimulations of the neostriatum lead to resistance against extinction of learned responses (Herz et al., 1974; Kolb, 1977).

Mayberg et al. (1992) found lateral orbitofrontal hypometabolism on PET scans of depressed, but not euthymic $\mathrm{HD}$ patients. These findings can be considered in conjunction with the loss of neurons in the locus coeruleus, but not median raphe, in HD, suggesting that the neurotransmitter depletion involved in the depression may be norepinephrine rather than serotonin (Zweig et al., 1992).

Emotional problems in HD presumably also result from disconnections of the orbitofrontal-CN neural system from limbic structures, especially the hypothalamus and amygdala and their connections. This might explain the greater responsiveness of HD patients to external than to internal stimuli, since the hypothalamus and amygdala are thought to be important in the generation of primary drives or emotions, and these primary drives seem preserved.

\section{CONCLUSIONS}

We have presented a summary of nonmotor behavioral findings in HD as well as a theoretical framework for considering the findings related to dysfunction of the $\mathrm{CN}$ or $\mathrm{CN}$-synapsing loops, whereas motor behaviors may be related more closely to dysfunction of the motor loop. In addition, we have presented animal studies which support an independent role for the $\mathrm{CN}$ in behaviors that are very similar to those seen in HD. We have proposed that a caudate-limbic disconnection may account for emotional changes seen in HD. Could such a disconnection also account for other behavioral changes?

Sarter and Markowitsch (1985) proposed a role for the amygdala in memory processing in which the amygdala was important for retrieval of memories which had been encoded with emotional colorization (declarative memories), but was unimportant for retrieval of memories which did not depend on an emotional element (semantic or generic memories). Based on this hypothesis, the inability of HD patients to retrieve emotionally important memories may be due to disconnexion of the $\mathrm{CN}$ from the amygdala. In contrast, $\mathrm{AD}$ patients appear to have lost semantic memories as well, most likely due to degradation of different neural structures which are responsible for encoding, storing, or retrieving memories of all types, be they of emotional significance or not.

"Executive function" includes the ability to plan and to switch cognitive sets. It depends upon goal-setting. HD patients may not be able to formulate a plan because their primary drive or motivational system for thirst, hunger and other basic drives, which probably emanates from the hypothalamus, amygdala, or other limbic structures, is disconnected from higher order association cortices that are capable of cognitively developing a strategy to fulfil those primary drives.

Visuospatial abnormalities in HD include loss of egocentric spatial representations with sparing of the ability to copy complex figures. An egocentric spatial map, by definition, involves information defined in a highly personal way and could well require limbic information, or be disrupted by a lesion disconnecting limbic structures. Copying a Rey-Osterreith Complex Figure which does not require knowledge of an emotional nature can be performed by HD patients.

Language functions, including syntax and most aspects of semantics, are spared in HD, but prosody and motivational aspects of speech are impaired. Thus, language and paralinguistic aspects of speech may be processed differently, with the neostriatum affecting primarily the latter, more emotional component of language. Errors of visual naming do not imply a semantic problem, but may reflect a unimodal visual representational problem in the tail of the $\mathrm{CN}$ or its temporal lobe connections.

If the caudate-synapsing loops receive input from the amygdala, amygdala lesions should produce deficits similar to HD. Tranel and Hyman (1990) reported a patient with Urbach-Wiethe disease, a disease which produces bilateral amygdala damage. Their patient had problems with executive function, memory, verbal fluency, digit span, and modulation of social and emotional behavior, all of which are also abnormal in HD. Also like HD, language functions in their patient were reportedly normal. Unlike HD however, prosody, and skill-learning were normal. These findings may reflect the nonparticipation of $\mathrm{CN}$ in motoric tasks, such as the production of prosody and motor learning, which alternatively might occur due to damage to the PUT or motor loop, or by other structures.

The ventral striatum, part of the so-called "limbic striatum" (Heimer et al., 1982), has connections with both the amygdala and the $\mathrm{CN}$, and would seem a natural culprit. However, neuropathological studies have shown that the ventral striatum is largely spared in HD (Vonsattel et al., 1985; Roos, 1986). One exception is the finding of nuclear membrane indentations in ultrastructural examinations of ventral striatums in HD, but these findings are not presently correlated with abnormal function (Bots and Bruyn, 1981; Roos and Bots, 1983).

Direct amygdalostriatal projections in primates and cats terminate in the tail, head and body of the $\mathrm{CN}$ as well as the ventral PUT (Price and Amaral, 1981; Kelley et al., 1982; Russchen and Price, 1984; Russchen et al., 1985), and offer an alternative pathway that is potentially damaged in $\mathrm{HD}$. The same parts of the tail and head of the $\mathrm{CN}$ also receive orbitofrontal, anterior cingulate and superior temporal cortical projections (Selemon and Goldman-Rakic, 
1985). Moreover, the cingulum and orbitofrontal cortex receive projections from the amygdala (Isaacson, 1982). Thus the parts of the CN known to be affected earliest and most severely in HD have extensive limbic connections, and their involvement is consistent with a $\mathrm{CN}$-limbic disconnection hypothesis.

$\mathrm{CN}$ lesions seem to differentially affect the personal and generic aspects of experience possibly by means of a $\mathrm{CN}$ limbic disconnection. The nature of the deficits in HD suggest that utilizing semantic strategies for rehabilitation may be of clinical benefit.

\section{Acknowledgement}

The authors thank Kenneth Heilman and Jeffrey Shuren for reading the manuscript and making suggestions.

\section{REFERENCES}

Albert MS, Butters N and Brandt J (1981) Patterns of remote memory in amnesic and demented patients. Archives of Neurology, 38, 495-500.

Alexander GE, DeLong MR and Strick PL (1986) Parallel organisation of functionally segregated circuits linking basal ganglia and cortex. Annual Review of Neuroscience, 9, 357-381.

Alzheimer A (1911) Uber die anatomische Grundlage der Huntington'schen Chorea und der chorea tischen Bewegungen Uberhaupt. Zeitschrift für die gesante Neurologie und Psychiatrie, 3, 566-567.

Aylward EH, Karagiozis H, Pearlson G and Folstein MF (1991) Suprasellar cistern measures as a reflection of dementia in Alzheimer's disease but not Huntington's disease. Journal of Psychiatric Research, 25, 31-47.

Bamford KA, Caine ED, Kido DK, Plassche WM and Shoulson I (1989) Clinical-pathologic correlation in Huntington's disease: a neuropsychologic and computed tomography study. Neurology, 39, 796-780.

Bayles KA and Kaszniak AW (1987) Communication and Cognition in Normal Aging and Dementia. Little, Brown and Company, Boston.

Bayles KA and Tomoeda CK (1983) Confrontation naming impairment in dementia. Brain and Language, 19, 98-114.

Beatty WW and Butters N (1986) Further analysis of encoding in patients with Huntington's disease. Brain and Cognition, 5, 387-398.

Benton A (1985) Visuoperceptual, visuospatial and visuoconstructive disorders. In: Clinical Neuropsychology, 2nd Edn (Eds KM Heilman and E Valenstein), p.179. Oxford University Press, New York.

Berent S, Giordani B, Lehtinen S, Markel D, Penney B, Buchtel HA, Starosta-Rubinstein S, Hichwa R and Young AB (1988) Positron emission tomographic scans of Huntington's disease: cerebral metabolic correlates of cognitive function. Annals of Neurology, 23, 541-546.

Bots GThAM and Bruyn GW (1981) Neuropathological changes of the nucleus accumbens in Huntington's chorea. Acta Neuropathologica, 55, 21-22.

Brandt J (1985) Access to knowledge in the dementia of Huntington's disease. Journal of Neuropsychology, 1, 335-338.

Brouwers P, Cox C, Martin A, Chase TN and Fedio P (1984) Differential perceptual-spatial impairment in Huntington's and Alzheimer's dementias. Archives of Neurology, 41, 1073-1076.
Bruyn GW, Bots GThAM and Dom R (1979) Huntington's chorea: current neuropathologic status. In: Advances in Neurology, Vol. 23, Huntington's Disease (Eds TN Chase, NS Wexler and A Barbeau), pp. 83-93. Raven Press, New York. Butters N and Albert MS (1982) Processes underlying failures to recall remote events. In: Human Memory and Amnesia (Ed. LS Cermak). Erlbaum, Hillsdale, NJ.

Butters N, Tarlow S, Cermak L and Sax D (1976) A comparison of the information processing deficits of patients with Huntington's chorea and Korsakoff's syndrome. Cortex, 12 134-144.

Butters N, Sax D, Montgomery K and Tarlow S (1978) Comparison of neuropsychological deficits associated with early and advanced Huntington's disease. Archives of Neurology, 35, 585-589.

Butters N, Albert MS, Sax DS, Miliotis P, Nagode J and Sterste A (1983) The effect of verbal mediators on the pictorial memory of brain-damaged patients. Neuropsychologia, 21, 307-323.

Butters N, Wolfe J, Granholm E and Martone M (1986) An assessment of verbal recall, recognition, and fluency abilities in patients with Huntington's disease. Cortex, 86, 11-32.

Butters N, Granholm E, Salmon DP and Grant I (1987) Episodic and semantic memory: a comparison of amnesic and demented patients. Journal of Clinical and Experimental Neuropsychology, 9, 479-497.

Caine ED and Shoulson I (1983) Psychiatric syndromes in Huntington's disease. American Journal of Psychiatry, 140, 728-733.

Caine ED, Ebert MH and Weingartner H (1977) An outline for the analysis of dementia: the memory disorder of Huntington's disease. Neurology, 27, 1087-1092.

Caine ED, Hunt RD, Weingartner H and Ebert MH (1978) Huntington's dementia: clinical and neuropsychological features. Archives of General Psychiatry, 35, 377-384.

Caine ED, Bamford KA, Schiffer RB, Shoulson I and Levy S (1986) A controlled neuropsychological comparison of Huntington's disease and multiple sclerosis. Archives of Neurology, 43, 249-254.

Cummings JL (Ed.) (1990) Subcortical Dementia. Oxford University Press, New York.

De La Monte SM, Vonsattel JP and Richardson EP (1988) Morphometric demonstration of atrophic changes in the cerebral cortex, white matter, and neostriatum in Huntington's disease. Journal of Neuropathology and Experimental Neurology, 47, 515-525.

Delgado JMR (1963) Cerebral heterostimulation in a monkey colony. Science, 141, 161-163.

Delgado JMR (1979) Inhibitory functions in the neostriatum. In: The Neostriatum (Eds I Divac and RGE Oberg). Pergamon Press, Oxford.

Divac I (1972) Delayed alternation in cats with lesions of the prefrontal cortex and the caudate nucleus. Physiology and Behavior, 8, 519-522.

Divac I, Rosvold HE and Szwarcbart MK (1967) Behavioral effects of selective ablation of the caudate nucleus. Journal of Comparative and Physiological Psychology, 63, 184-190.

Divac I, Markowitsch HJ and Pritzel M (1978) Behavioral and anatomical consequences of small intrastriatal injections of kainic acid in the rat. Brain Research, 151, 523-532.

Eslinger PJ and Damasio AR (1986) Preserved motor learning in Alzheimer's disease: implications for anatomy and behavior. Journal of Neuroscience, 6, 3006-3009.

Fedio P, Cox CS, Neophytides A, Canal-Frederick G and Chase TN (1979) Neuropsychological profile of Huntington's dis- 
ease: patients and those at risk. In: Advances in Neurology, Vol. 23, Huntington's Disease (Eds TN Chase, NS Wexler and A Barbeau), pp. 239-256. Raven Press, New York.

Ferrante RJ, Kowall NW, Beal MF, Richardson EP Jr, Bird ED and Martin JB (1985) Selective sparing of a class of striatal neurons in Huntington's disease. Science, 230, 561-563.

Folstein SE (1991) The psychopathology of Huntington's disease. In: Genes, Brain, and Behavior (Eds PR McHugh and VA McKusick), pp. 181-191. Raven Press, New York.

Folstein MF and McHugh PR (1983) The neuropsychiatry of some specific brain disorders. In: Handbook of Psychiatry, Vol. 2, Mental Disorders and Somatic Illness (Ed. MH Lader), pp. 107-118. Cambridge University Press, Cambridge.

Folstein SE, Brandt J and Folstein MF (1990) Huntington's disease. In: Subcortical Dementia (Ed. J Cummings), pp. 87-107. Oxford University Press, Oxford.

Fuster JM (1989) The Prefrontal Cortex: Anatomy, Physiology and Neuropsychology of the Frontal Lobe, 2nd Edn. Raven Press, New York.

Goldman-Rakic PS (1987) Circuitry of primate prefrontal cortex and regulation of behavior by representational memory. In: Handbook of Physiology, Sect. 1, The Nervous System, Vol. 5, Higher Functions of the Brain, Pt I (Eds Sect., VB Mountcastle; Vol., F Plum), pp. 373-417. Waverly Press, Baltimore.

Gordon WP and Illes J (1987) Neurolinguistic characteristics of language production in Huntington's disease: a preliminary report. Brain and Language, 31, 1-10.

Grafton ST, Mazziotta JC, Pahl, JJ, et al. (1990) A comparison of neurologic, metabolic, structural and genetic evaluations in persons at risk for Huntington's disease. Annals of Neurology, 28, 614-621.

Granholm E and Butters N (1988) Associative encoding and retrieval in Alzheimer's and Huntington's disease. Brain and Cognition, 7, 335-347.

Harper PS (Ed.) (1991) Huntington's Disease. WB Saunders, Philadelphia.

Heilman KM, Scholes R and Watson RT (1975) Auditory affective agnosia: disturbed comprehension of affective speech. Journal of Neurology, Neurosurgery and Psychiatry, 38, 69-72.

Heimer L, Switzer RD and Van Hoesen GW (1982) Ventral striatum and ventral pallidum: components of the motor system? Trends in Neuroscience, 5, 83-87.

Heindel WC, Butters N and Salmon DP (1988) Impaired learning of a motor skill in patients with Huntington's disease. Behavioral Neuroscience, 102, 141-147.

Heindel WC, Salmon DP, Shults CW, Walicke PA and Butters N (1989) Neuropsychological evidence for multiple implicit memory systems: a comparison of Alzheimer's, Huntington's, and Parkinson's disease patients. Journal of Neuroscience, 9, 582-587.

Heindel WC, Salmon DP and Butters N (1990) Pictorial priming and cued recall in Alzheimer's and Huntington's disease. Brain and Cognition, 13, 282-295.

Herz MJ, Marshall KE and Peeke HVS (1974) Brain stimulation and behavior: controls and consequences. Physiological Psychology, 2, 184-186.

Hodges JR, Salmon DP and Butters N (1990) Differential impairment of semantic and episodic memory in Alzheimer's and Huntington's diseases: a controlled prospective study. Journal of Neurology, Neurosurgery and Psychiatry, 53, 1089-1095.

Hodges JR, Salmon DP and Butters N (1991) The nature of the naming deficit in Alzheimer's and Huntington's disease. Brain, 114, 1547-1558.

Huntington G (1872) On chorea. Medical and Surgical Reporter, 26, 320-321, republished (1973) Advances in Neurology, Vol. 1, Huntington's Chorea (Eds A Barbeau, TN Chase and GW Paulson), pp. 33-35. Raven Press, New York.

Isaacson RL (1982) The Limbic System. Plenum Press, New York. Jason G, Pajurkava E, Suchowersky O, et al. (1988) Presymptomatic neuropsychologic impairment in Huntington's disease. Archives of Neurology, 45, 769-773.

Jelgersma G (1908) Die anatomische Ueranderungen bei Paralysis agitans und chronischer chorea. Verhandlungen der Gesellschaft deutscher Naturforscher und Arzte, 2, 383-388.

Jernigan TL, Salmon DP, Butters N and Hesselink JR (1991) Cerebral structure on MRI, part II: specific changes in Alzheimer's and Huntington's diseases. Biological Psychiatry, 29, 68-81.

Johnson TN and Rosvold HE (1971) Topographic projections on the globus pallidus and the substantia nigra of selectively placed lesions in the precommissural caudate nucleus and putamen in the monkey. Experimental Neurology, 33, 584-596.

Josiassen RC, Curry LM and Mancall EL (1983) Development of neuropsychological deficits in Huntington's disease. Archives of Neurology, 40, 791-796.

Kelley AE, Domesick VB and Nauta WJH (1982) The amygdalostriatal projection in the rat-an anatomical study by anterograde and retrograde tracing methods. Neuroscience, 7 , 615-630.

Kinnier Wilson SA (1914) An experimental research into the anatomy and physiology of the corpus striatum. Brain, 36, 427-492.

Kitsikis A and Rougeul A (1968) The effect of caudate stimulation on conditioned motor behavior in monkeys. Physiology and Behavior, 3, 831-837.

Knopman D and Nissen MJ (1991) Procedural learning is impaired in Huntington's disease: evidence from the serial reaction time task. Neuropsychologia, 29, 245-254.

Kolb B (1977) Studies on the caudate-putamen and the dorsomedial thalamic nucleus of the rat: implications for mammalian frontal-lobe functions. Physiology and Behavior, 18, 237-244.

Kuwert T, Lange HW, Langen K, Herzog H, Aulich A and Feinendegen LE (1990) Cortical and subcortical glucose consumption measured by PET in patients with Huntington's disease. Brain, 113, 1405-1423.

Lyle O and Quast W (1976) The Bender gestalt: use of clinical judgment versus recall scores in prediction of Huntington's disease. Journal of Consulting and Clinical Psychology, 44, 229-232.

Martin JB and Gusella JF (1986) Huntington's disease: pathogenesis and management. New England Journal of Medicine, 315, 1267-1276.

Martone M, Butters N, Payne M, Becker JT and Sax DS (1984) Dissociations between skill learning and verbal recognition in amnesia and dementia. Archives of Neurology, 41, 965-970.

Massman PJ, Delis DC and Butters N (1990) Are all subcortical dementias alike?: Verbal learning and memory in Parkinson's and Huntington's disease patients. Journal of Clinical and Experimental Neuropsychology, 12, 729-744.

Mayberg HS, Starkstein SE, Peyser CE, Brandt J, Dannals RF and Folstein SE (1992) Paralimbic frontal lobe hypometabolism in depression associated with Huntington's disease. Neurology, 42, 1791-1797. 
Mazziotta JC, Phelps ME, Pahl JJ, Huang SC, Baxter LR, Riege WH, Hoffman JM, Kuhl DE, Lanto AB, Wapenski JA and Markham CH (1987) Reduced cerebral glucose metabolism in asymptomatic subjects at risk for Huntington's disease. New England Journal of Medicine, 316, 357-362.

Mindham RHS, Steele C, Folstein MF and Lucas J (1985) A comparison of the frequency of major affective disorder in Huntington's disease and Alzheimer's disease. Journal of Neurology, Neurosurgery, and Psychiatry, 48, 1172-1174.

Mohr E, Brouwers P, Claus JJ, Mann UM, Fedio P and Chase TN (1991) Visuospatial cognition in Huntington's disease. Movement Disorders, 6, 127-132.

Moss MB, Albert MS, Butters N and Payne M (1986) Differential patterns of memory loss among patients with Alzheimer's disease, Huntington's disease, and alcoholic Korsakoff's syndrome. Archives of Neurology, 43, 239-246.

Myers RH, Vonsattel JP, Paskevich PA, Kiely DK, Stevens TJ, Cupples LA, Richardson EP and Bird ED (1991) Decreased neuronal and increased oligodendroglial densities in Huntington's disease caudate nucleus. Journal of Neuropathology and Experimental Neurology, 50, 729-742.

Norton JC (1975) Patterns of neuropsychological performance in Huntington's disease. Journal of Nervous and Mental Disease, 161, 276-279.

Parent A (1990) Extrinsic connections of the basal ganglia. Trends in Neuroscience, 13, 254-258.

Penney JB, Young AB, Shoulson I, et al. (1990) Huntington's disease in Venezuela: 7 years of follow-up of symptomatic and asymptomatic individuals. Movement Disorders, 5, 93-99.

Phillips AG (1979) Electrical Stimulation of the Neostriatum in Behaving Animals (Eds I Divac and RGE Oberg), pp. 183-194. Pergamon Press, Oxford.

Pillon B, Dubois B, Ploska A and Agid Y (1991) Severity and specificity of cognitive impairment in Alzheimer's, Huntington's, and Parkinson's diseases and progressive supranuclear palsy. Neurology, 41, 634-643.

Podoll K, Caspary P, Lange HW and Noth J (1988) Language functions in Huntington's disease. Brain, 111, 1475-1503.

Potegal M (1971) A note on spatial-motor deficits in patients with Huntington's disease: test of a hypothesis. Neuropsychologia, 9, 233-235.

Price JL and Amaral DG (1981) An autoradiographic study of the projections of the central nucleus of the monkey amygdala. Journal of Neuroscience, 1, 1242-1259.

Reiner A, Albin RL, Anderson KD et al. (1988) Differential loss of striatal projection neurons in Huntington's disease. Proceedings of the National Academy of Sciences, U.S.A., 85, 5733-5737.

Roos RAC (1986) Neuropathology of Huntington's chorea. In: Handbook of Clinical Neurology, Vol. 5 (49), Extrapyramidal Disorders (Eds PJ Vinken, GW Bruyn and HL Klawans), pp. 315-326. Elsevier, Amsterdam.

Roos RAC and Bots GThAM (1983) Nuclear membrane indentations in Huntington's chorea. Journal of the Neurological Sciences, 61, 37-47.

Ross ED and Mesulam M-M (1979) Dominant language functions of the right hemisphere? Prosody and emotional gesturing. Archives of Neurology, 36, 144-148.

Russchen FT, Bakst I, Amaral DG and Price JL (1985) The amygdalostriatal projections in the monkey. An anterograde tracing study. Brain Research, 329, 241-257.

Russchen FT and Price JL (1984) Amygdalostriatal projections in the rat. Topographical organization and fiber morphology shown using the lectin PHA-L as an anterograde tracer. Neuroscience Letters, 47, 15-22.

Salmon DP, Shimamura AP, Butters N and Smith S (1988) Lexical and semantic priming defects in patients with Alzheimer's disease. Journal of Clinical and Experimental Neuropsychology, 10, 477-494.

Sarter M and Markowitsch HJ (1985) The amygdala's role in human mnemonic processing. Cortex, 21, 7-24.

Schmahmann JD (1991) An emerging concept: the cerebellar contribution to higher function. Archives of Neurology, 48, 1178-1187.

Schoenfeld M, Myers RM, Cupples A, Berkman B, Sax DS and Clark E (1984) Increased rate of suicide among patients with Huntington's disease. Journal of Neurology, Neurosurgery and Psychiatry, 47, 1283-1287.

Selemon LD and Goldman-Rakic PS (1985) Longitudinal topography and interdigitation of corticostriatal projections in the rhesus monkey. Journal of Neuroscience, 5, 776-794.

Shinamura AP, Salmon DP, Squire LR and Butters N (1987) Memory dysfunction and word priming in dementia and amnesia. Behavioral Neuroscience, 101, 347-351.

Shoulson I (1990) Huntington's disease: cognitive and psychiatric features. Neuropsychiatry, Neuropsychology and Behavioral Neurology, 3, 15-22.

Smith S, Butters N, White R, Lyon L and Granholm E (1988) Priming semantic relations in patients with Huntington's disease. Brain and Language, 33, 27-40.

Speedie LJ, Brake N, Folstein SE, Bowers D and Heilman KM (1990) Comprehension of prosody in Huntington's disease. Journal of Neurology, Neurosurgery and Psychiatry, 53, 607-610.

Starkstein SE, Brandt J, Folstein SE, Strauss M, Berthier ML, Pearlson GD, Wong D, McDonnell A and Folstein MF (1988) Neuropsychological and neuroradiological correlates in Huntington's disease. Journal of Neurology, Neurosurgery and Psychiatry, 51, 1259-1263.

Starkstein S, Folstein SE, Brandt J, Pearlson G, McDonnell A and Folstein MF (1989) Brain atrophy in Huntington's disease. A CT-scan study. Neuroradiology, 31, 156-159.

Tranel D and Hyman BT (1990) Neuropsychological correlates of bilateral amygdala damage. Archives of Neurology, 47, 349-355.

Troster AI, Salmon DP and Butters N (1989) A comparison of the category flluency deficits associated with Alzheimer's and Huntington's disease. Brain and Language, 37, 500-513.

Tulving E and Schacter DL (1990) Priming and human memory systems. Science, 247, 301-306.

Van Buren JM (1963) Confusion and disturbance of speech from stimulation in the vicinity of the head of the caudate nucleus. Journal of Neurosurgery, 20, 148-157.

Vonsattel J-P, Myers RH, Stevens TJ, Ferrante RJ, Bird ED and Richardson EP, Jr (1985) Neuropathological classification of Huntington's disease. Journal of Neuropathology and Experimental Neurology, 44, 559-577.

Wexler NS (1979) Perceptual-motor, cognitive, and emotional characteristics of persons at risk for Huntington's disease. In: Advances in Neurology, Vol. 23, Huntington's Disease (Eds TN Chase, NS Wexler and A Barbeau), pp. 257-272. Raven Press, New York.

Young AB, Penney JB, Starosta-Rubinstein S, Markel DS, Berent S, Giordani B, Ehrenkaufer R, Jewett D and Hichwa R (1986) PET scan investigations of Huntington's disease: cerebral metabolic correlates of neurological features and functional decline. Annals of Neurology, 20, 296-303. 
Young AB, Penney JB, Starosta-Rubinstein S, Markel DS, Berent S, Giordani B, Rothley J, Betley A and Hichwa R (1987) Normal caudate glucose metabolism in persons at risk for Huntington's disease. Archives of Neurology, 44, 254-7.
Zweig RM, Ross CA, Hedreen, JC, Peyser C, Cardillo JE, Folstein SE and Price DL (1992) Locus coeruleus involvement in Huntington's disease. Archives of Neurology, 49, 152-156. 


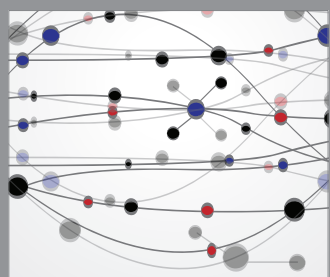

The Scientific World Journal
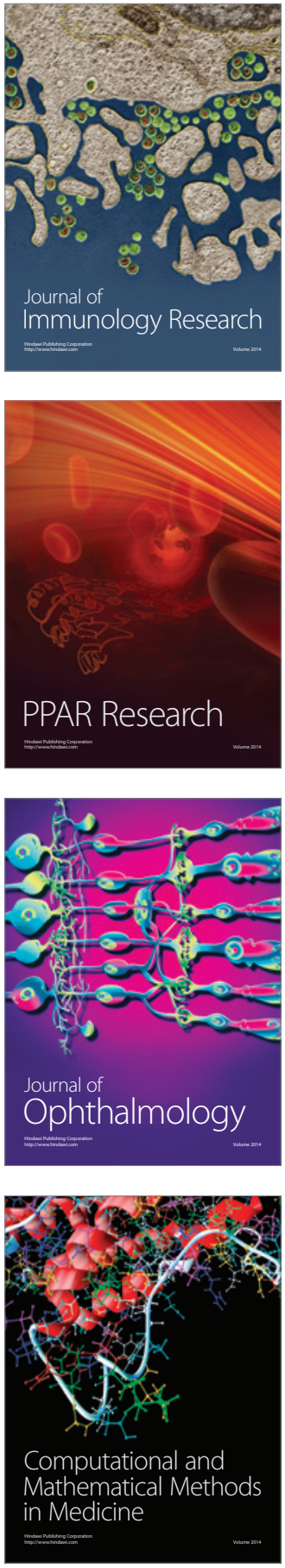

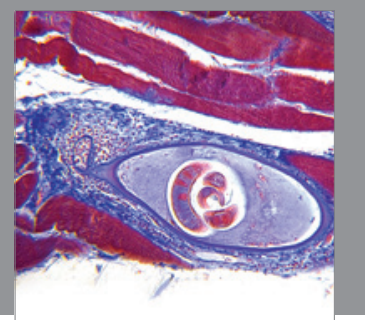

Gastroenterology

Research and Practice
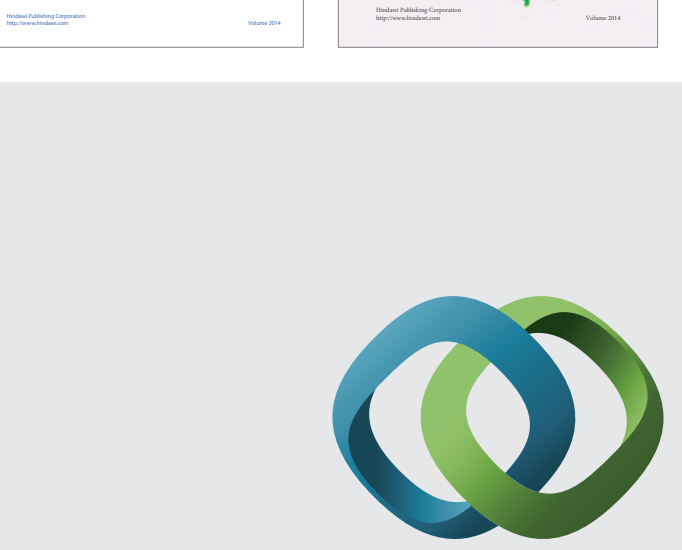

\section{Hindawi}

Submit your manuscripts at

http://www.hindawi.com
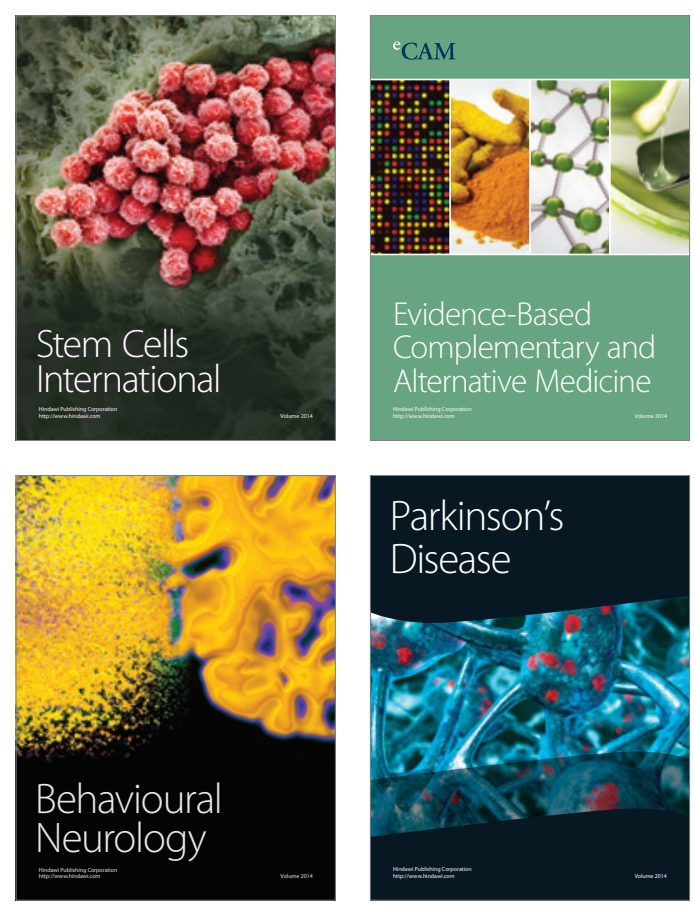

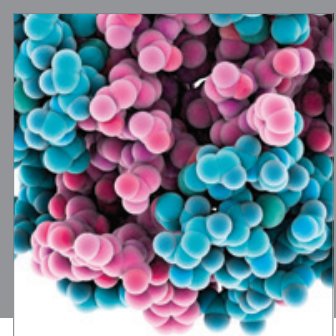

Journal of
Diabetes Research

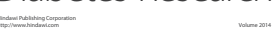

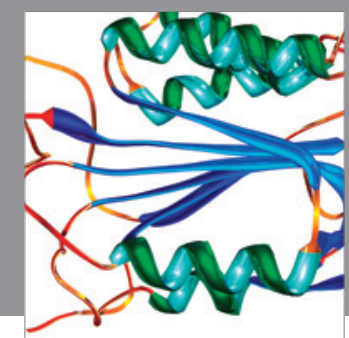

Disease Markers
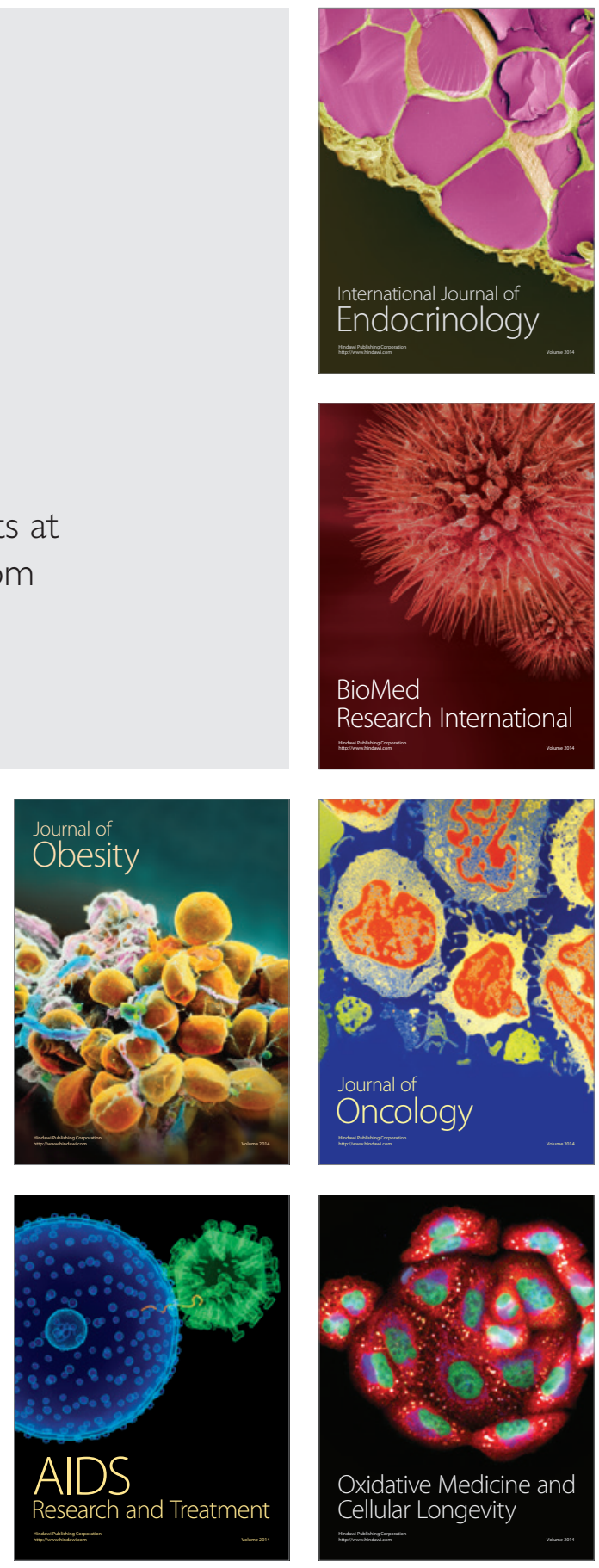